\title{
Effect of cationic surfactant on homogenization and polymerization of methyl methacrylate miniemulsion modified by chitosan
}

\author{
Jauder Jeng, ${ }^{1}$ Chi-An Dai, ${ }^{1,2}$ Wen-Yen Chiu ${ }^{1,2 *}$ and Pin-Yen Young ${ }^{3}$ \\ ${ }^{1}$ Institute of Polymer Science and Engineering, National Taiwan University, Taipei, Taiwan, Republic of China \\ ${ }^{2}$ Department of Chemical Engineering, National Taiwan University, Taipei, Taiwan, Republic of China \\ ${ }^{3}$ Four Pillars Enterprise Company Ltd, Taipei, Taiwan, Republic of China
}

\begin{abstract}
Homogenization of monomer droplets and polymerization of methyl methacrylate (MMA) miniemulsion, stabilized by a combination of cationic surfactants including different amounts of $n$-hexadecyltrimethylammonium chloride (HTMA) and chitosan 100, were investigated. With increasing HTMA concentration or decreasing concentration of chitosan 100 , the required ultrasonication time for the miniemulsion to reach a critically stabilized state is reduced. After polymerization, for higher HTMA concentrations, droplet nucleation dominates because of higher surface coverage of HTMA on the droplets. However, for lower HTMA concentrations, the size distributions (SDs) of final latex particles are different from those of the droplets. Because surface coverage of HTMA on the droplets is lower in this condition, both droplet nucleation and homogeneous and/or micellar nucleation occur simultaneously in the miniemulsion polymerization. On increasing the concentration of chitosan 100 in the system, the SD of the final latex particles is far different from that of the droplets. This is due to a decrease of the effective surface coverage of chitosan 100 and HTMA on the droplets. Consequently, the opportunity of collision coalescence of the droplets increases, and MMA molecules can diffuse out more easily into the aqueous phase. Droplet nucleation is, therefore, no longer the major source for the latex particles.
\end{abstract}

(C) 2006 Society of Chemical Industry

Keywords: miniemulsion; surfactant effect; chitosan; particle size distribution

\section{INTRODUCTION}

The choice of surfactant is one of the important factors as regards the stability of a miniemulsion and its subsequent polymerization. It has been proved a number of times that the monomer droplet size decreases with increasing surfactant concentration. ${ }^{1-10}$ While the droplet size decreases, the total surface area of the droplets increases markedly. Consequently, the droplets can capture radicals from an aqueous phase more efficiently, and homogeneous and/or micellar nucleation is thus suppressed. ${ }^{3,4,11}$ However, the droplet size cannot be reduced indefinitely by increasing the amount of surfactant. ${ }^{3}$ Instead, micelles are formed in the aqueous phase. When micelles are present, it is detrimental for droplet nucleation in miniemulsion polymerization.

The surface coverage of polymerized latex particles (covered with surfactant molecules) is related to the surfactant concentration. The higher the surfactant concentration, the denser the surface coverage of the polymerized latex particles. ${ }^{1,2}$ Also, the average size of the polymerized latex particles decreases with increasing surfactant concentration. ${ }^{1-4}$
Polymeric surfactants, like dextran, ${ }^{12,13}$ chitosan, ${ }^{14-20}$ and poly(sodium acrylate), ${ }^{21}$ are often applied to study the stability of emulsions, which is related to the concentration and molecular weight of the polymeric surfactants. Using dextrans as polymeric surfactants to synthesize poly(butyl 2-cyanoacrylate) (PBCA) nanoparticles, Douglas et al. ${ }^{12}$ showed, first, that in a certain region the higher the concentration of the dextran, the smaller the average nanoparticle size of PBCA, and, second, that the larger the molecular weight of the dextran, the smaller the average nanoparticle size. They proposed that sterically repulsive energy was an important factor for the nanoparticle size of PBCA. The concentration of the dextran in the protective surface layer of the PBCA nanoparticles depended upon the bulk concentration of the dextran and the affinity of the dextran molecules on the nanoparticle surface. Thickness of the protective layer of the dextran increased with increasing molecular weight of the dextran. The stabilizing effects of the dextran, consequently, increased with its molecular weight. $^{12}$

Miniemulsion polymerization has been studied extensively, including preparation of fluorinated

* Correspondence to: Wen-Yen Chiu, Institute of Polymer Science and Engineering, National Taiwan University, Taipei, Taiwan, Republic of China E-mail: ycchiu@ccms.ntu.edu.tw

(Received 1 June 2006; revised version received 27 July 2006; accepted 16 October 2006)

Published online 29 December 2006; DOI: 10.1002/pi.2199 
latex ${ }^{22}$ and magnetic latex, ${ }^{23}$ nitroxide-mediated living free radical miniemulsion polymerization, ${ }^{24}$ reversible addition-fragmentation chain transfer, ${ }^{25}$ and atom transfer radical polymerization. ${ }^{26}$ However, nucleation and growth of the latex particles for miniemulsion polymerization have still not been fully investigated. In the present work, we studied the effect of the cationic surfactant concentration on the size distribution of the monomer droplets and on the growth mechanism of latex particles in methyl methacrylate (MMA) miniemulsion polymerization.

\section{EXPERIMENTAL \\ Materials}

MMA monomer was distilled under reduced pressure and stored at $-5{ }^{\circ} \mathrm{C}$ before use. A mixture of cationic surfactants, $n$-hexadecyltrimethylammonium chloride (HTMA) and chitosan 100, was used to prepare miniemulsions. Commercial-grade chitosan 100 was characterized by a deacetylation ratio $>80 \mathrm{~mol} \%$ after drying and a viscosity of ca $50-150 \mathrm{mN} \mathrm{s} \mathrm{m}^{-2}$ (with a concentration of $5 \mathrm{~g} \mathrm{~L}^{-1}$ at $20^{\circ} \mathrm{C}$ ). Deionized water was used. An oil-soluble initiator, 2,2'-azobis-(2,4dimethylvaleronitrile) (V-65), was obtained from Wako Company. Acetic acid (Aldrich), hexadecane (ACROS), chitosan 100 (Wako), hydroquinone (ACROS), HTMA (TCI), and V-65 were used without further purification.

\section{Preparation of MMA miniemulsions}

All concentrations, shown in Table 1, were based on a total volume of $0.5 \mathrm{wt} \%$ of acetic acid aqueous solution. Preparation procedure of the miniemulsion was divided into three steps. In the first step, chitosan 100 was dissolved in $200 \mathrm{~g}$ of $0.5 \mathrm{wt} \%$ acetic acid aqueous solution. The solution was stirred for $12 \mathrm{~h}$, followed by the addition of HTMA to prepare an aqueous phase. In the second step, a mixture of MMA monomer, hexadecane, and V-65 was mixed for $10 \mathrm{~min}$ to prepare an oil phase, which was added subsequently to the aqueous phase, prepared from the first step. In the third step, the oil/water mixture was mixed for $10 \mathrm{~min}$ using a magnetic stir bar for pre-emulsification, followed by ultrasonication (Ultrasonic Processor 50H, maximum sonic power

Table 1. Recipes for miniemulsion and subsequent polymerization. All concentrations are based on total volume of $0.5 \mathrm{wt} \%$ of acetic aqueous solution

\begin{tabular}{lll}
\hline & \multicolumn{1}{c}{ Concentration } & \multicolumn{1}{c}{ Weight } \\
\hline $\begin{array}{l}\text { O.5 wt\% of acetic } \\
\text { aqueous solution }\end{array}$ & & $200 \mathrm{~g}$ \\
Chitosan 100 & $0,0.1$, or $0.2 \mathrm{wt} \%$ & $0,0.2$, or $0.4 \mathrm{~g}$ \\
HTMA & $0,2,4,6,10$, or & $0,0.13,0.26,0.39$, \\
& $30 \mathrm{mmol} \mathrm{L}^{-1}$ & 0.65, or $1.96 \mathrm{~g}$ \\
MMA & $1000 \mathrm{mmol} \mathrm{L}^{-1}$ & $20 \mathrm{~g}$ \\
Hexadecane & $67.5 \mathrm{mmol} \mathrm{L}^{-1}$ & $3.09 \mathrm{~g}$ \\
V-65 & $1.6 \mathrm{mmol} \mathrm{L}^{-1}$ & $0.084 \mathrm{~g}$ \\
\hline
\end{tabular}

density $=460 \mathrm{~W} \mathrm{~cm}^{-2}$, Dr Dielsher) in an ice bath. The amplitude of the ultrasonication was set at $100 \%$. The total weight and solid content of each batch of the miniemulsion was kept at about $225 \mathrm{~g}$ and $10 \mathrm{wt} \%$, respectively. The solid content was kept at a relatively low level in order to minimize collision coalescence of the droplets. The hexadecane content was kept higher than $10 \mathrm{wt} \%$ of the monomer in order effectively to retard Ostwald ripening. ${ }^{3,4}$ In order to prevent overheating during miniemulsification, the pre-emulsion was immersed in an ice bath to prevent MMA polymerization or other undesirable reactions. The actual temperature of the miniemulsion during ultrasonication was kept around $10^{\circ} \mathrm{C}$. The miniemulsion was prepared by ultrasonicating the pre-emulsion for various periods of time: 10, 20, $30,40,50$, and $60 \mathrm{~min}$. At the end of each time period, an aliquot of the emulsion was withdrawn for measurement of the size distribution (SD) of the droplets. The miniemulsification procedure and results were reproducible.

\section{Polymerization of MMA miniemulsion}

Polymerization of the miniemulsion was conducted by discharging the homogenized miniemulsion into a four-neck glass reactor, equipped with a water bath at constant temperature $\left(70^{\circ} \mathrm{C}\right)$, condenser apparatus, and a Teflon stirrer. The polymerization system was purged with ultra-pure nitrogen gas before the start of the polymerization and stirred at $200 \mathrm{rpm}$. Temperature of the system was monitored using a thermometer. The typical polymerization reaction was finished within $40 \mathrm{~min}$.

\section{Analytical methods}

SDs of monomer droplets, at different homogenization times, and final latex particles were measured with a Zetasizer (3000 $\mathrm{HS}_{\mathrm{A}}$, Malvern) at a fixed scattering angle of $90^{\circ}$. The basic principle for measuring SDs is based on the technique of dynamic light scattering (DLS). A laser with a wavelength of $633 \mathrm{~nm}$ was used for the experiment. A withdrawn sample was diluted with a solution saturated with MMA and HTMA to ensure that diffusion of MMA or HTMA from the monomer droplets or the growing latex particles into aqueous phase was not possible. ${ }^{27}$ An aliquot of sample, withdrawn from the miniemulsifying emulsion at a specific homogenization time, was mixed immediately with several drops of $1 \mathrm{wt} \%$ hydroquinone aqueous solution and immersed in an ice bath to stop the polymerization. The distribution of particle diameters was measured immediately.

Conversion of miniemulsion polymerization was determined by a gravimetric method. Transmission electron microscopy (TEM) was used to examine the morphology of the latex particles, using phosphotungstic acid as a staining agent to enhance image contrast. Surface tension of the miniemulsion and final latex was measured using a tensiometer (CBVP-A3, FACE). A sandblasted platinum plate with dimensions 
$24 \times 10 \times 0.2 \mathrm{~mm}^{3}$ was used. The surface tension for each miniemulsion sample was averaged over three measurements: a measurement for a fresh sample that was withdrawn immediately from the ultrasonicated miniemulsion and two for the sample conditioned for 1 and $2 \mathrm{~h}$, respectively. The difference between the three measurements was usually within $3 \%$.

\section{RESULTS AND DISCUSSION}

\section{Effect of HTMA concentration on SD of monomer droplets}

The effect of HTMA concentration on the evolution of the SD of monomer droplets during ultrasonicating of MMA pre-emulsions is shown in Fig. 1, plotted as cumulative volume (CV) fraction of the droplets as a function of their diameters. The $\mathrm{CV}$ fraction of the droplets with diameter equal to $d$ is read as the total volume fraction of the droplets with a diameter equal to or smaller than $d$. When only chitosan 100 is used as cationic surfactant ([HTMA] $=0$ and [chitosan 100] $=0.1 \mathrm{wt} \%$ as shown in Fig. 1(a)), a volume-average diameter of the droplets is as large as about $1 \mu \mathrm{m}$ after ultrasonication for $60 \mathrm{~min}$. This indicates that in this case the pre-emulsion cannot be mini mulsified quickly. For other cases when HTMA and chitosan 100 are used in combination as cationic surfactants, the droplet size, however, decreases rapidly, and the ultrasonication time required for the droplets to reach a steady-state SD is also considerably shortened. Taking the case of [HTMA] $=2 \mathrm{mmol} \mathrm{L}^{-1}$ and chitosan $100=0.1 \mathrm{wt} \%$ for instance (shown in Fig. 1(b)), the droplets reduce rapidly in diameter and approach the steady-state SD after ultrasonication for $40 \mathrm{~min}$. At the steady state, $70 \%$ of the droplets are smaller than $100 \mathrm{~nm}$ in diameter, and $30 \%$ range from 100 to $500 \mathrm{~nm}$ in diameter. The volume-average droplet diameter is about $90 \mathrm{~nm}$.

Figure 1(b)-(e) also show that the $\mathrm{CV}$ fraction of the droplets varies with ultrasonication time when $\left[\right.$ HTMA] $=2-30 \mathrm{mmol} \mathrm{L}^{-1}$ and chitosan $100=$ $0.1 \mathrm{wt} \%$. For [HTMA] $=2 \mathrm{mmolL}^{-1}$, in the early stage of the ultrasonication, e.g. for the ultrasonication time equaling to $20 \mathrm{~min}$, the droplets exhibit an overall broad SD ranging between $c a 20$ and $c a$ $400-600 \mathrm{~nm}$. With increasing ultrasonication time, the CV fraction of the smaller droplets, however, increases while that of the larger ones decreases. When the ultrasonication time is more than $40 \mathrm{~min}$, the droplets approach a steady-state distribution in size in which a narrower and unimodal SD results. For higher HTMA concentrations ([HTMA] $=6,10$, and $30 \mathrm{mmol} \mathrm{L}^{-1}$ ), the SDs of the droplets are similar to that for $[\mathrm{HTMA}]=2 \mathrm{mmol} \mathrm{L}^{-1}$. In addition, the higher the HTMA concentration, the shorter the ultrasonication time for the droplets to reach the steady-state SD.

Figure 2 shows the final steady-state SDs of the droplets for different HTMA concentrations in miniemulsions. With increasing HTMA concentra-
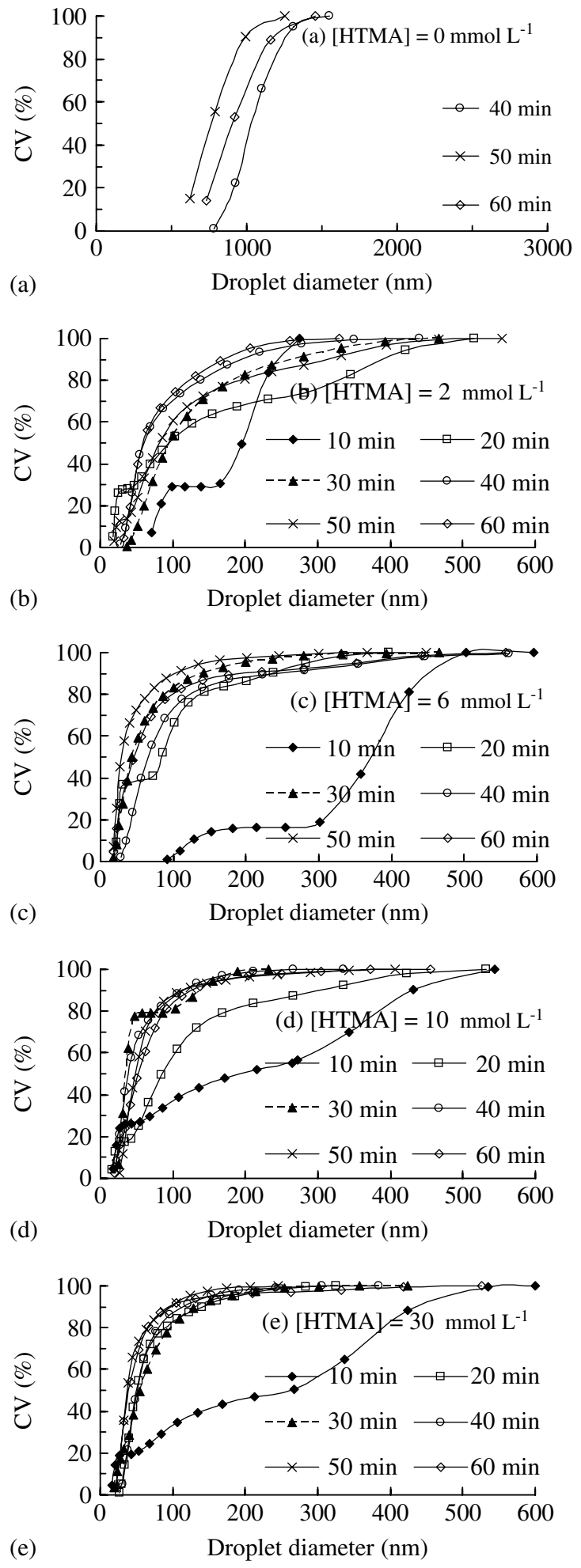

Figure 1. Size distributions of monomer droplets in MMA emulsions with chitosan $100=0.1$ wt $\%$ and HTMA concentrations as indicated.

tion, the SD of the droplets shifts towards lower values. It is ascribed to the decreasing opportunity of collision coalescence of the droplets, owing to increasing surface coverage of HTMA on the droplets. The droplets, therefore, reach the steady state faster, and the SD of the steady-state droplets shifts towards smaller droplet diameter with increasing HTMA concentration. 


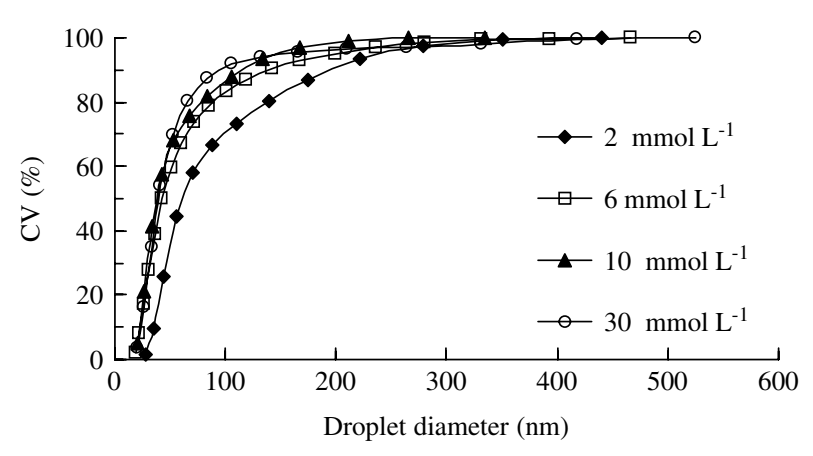

Figure 2. Cumulative volume, as a function of particle diameter, of the monomer droplets for critically stabilized miniemulsion with different concentrations of HTMA.

\section{Effect of concentration of chitosan 100 on size distribution of monomer droplets}

The concentration of chitosan 100 was varied, as listed in Table 2 for runs $\mathrm{CH} 1, \mathrm{H} 4$, and $\mathrm{CH} 2$, in order to study the effect of chitosan 100 on the SD of monomer droplets during ultrasonication. Results are shown in Fig. 3. The influence of ultrasonication time on the $\mathrm{SD}$ of the droplets is the same as that in Fig. 1, but the influence of the concentration of chitosan 100 is different from that of HTMA concentration described in the previous section. With increasing concentration of chitosan 100, the ultrasonication time for the SD of the droplets to arrive at a steady state is longer; in addition, the steady-state SD shifts towards larger droplet diameter, as shown in Fig. 4.

The structural unit of chitosan 100, a long-chain polymer, displayed in Fig. 5, is composed of a rigid and hydrophobic six-membered ring. In acidic aqueous solution, the $-\mathrm{NH}_{2}$ groups of chitosan 100 are ionized to $-\left(\mathrm{NH}_{3}\right)^{+}$groups. Although chitosan 100 or HTMA can be used as a cationic surfactant, their alignment on the droplet surface is different. Segments of chitosan 100 are too rigid to lie in order and closely on the droplet surface, but HTMA can. Based on both characteristics, an assumption is proposed that the segments of chitosan 100 cannot effectively cover the droplet surface. The bare surface cannot be filled completely by HTMA molecules either, owing to electrostatic repulsion. ${ }^{14}$ This means that the partial droplet surface, occupied by the segments of chitosan 100 , is bare. A schematic diagram using chitosan 100
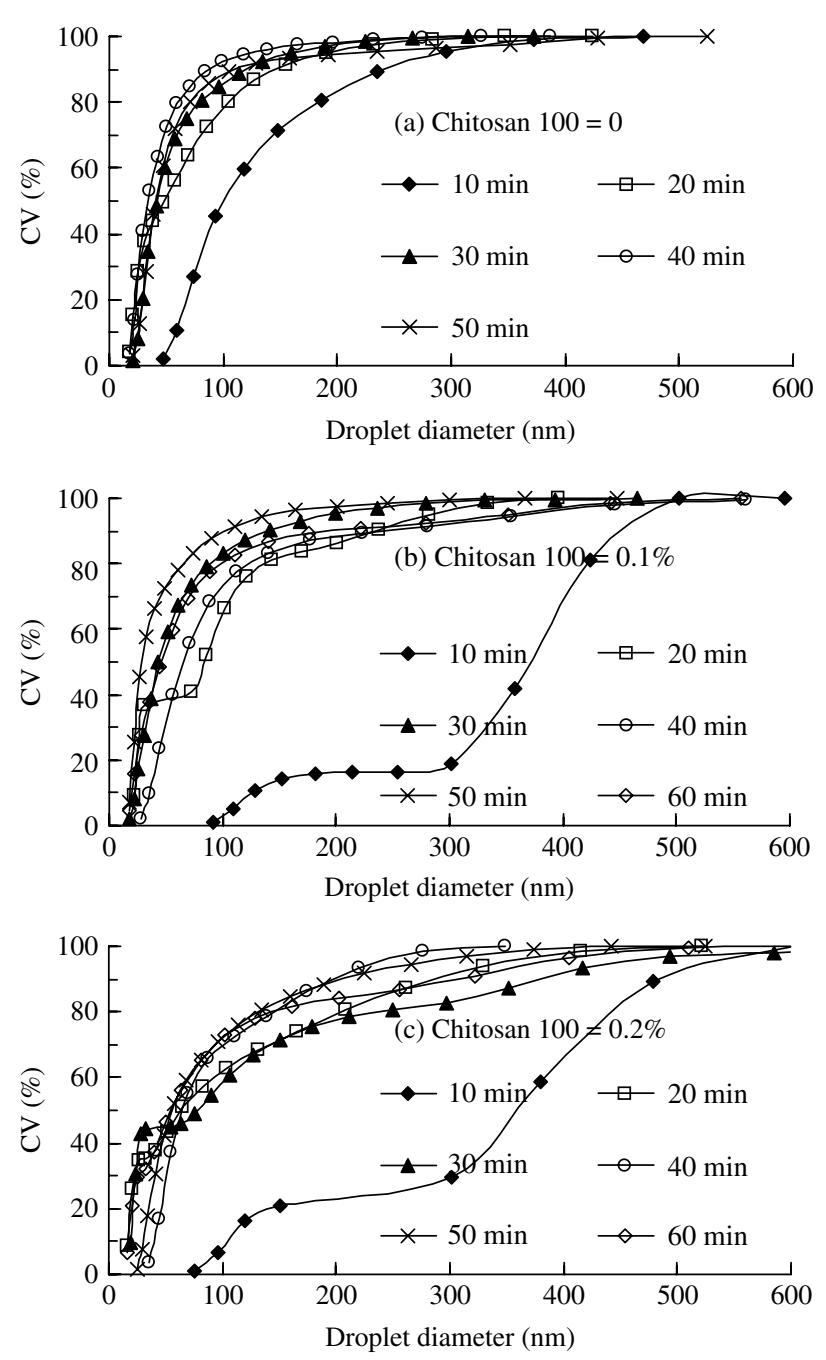

Figure 3. Size distributions of monomer droplets in MMA emulsions with $[\mathrm{HTMA}]=6 \mathrm{mmol} \mathrm{L}^{-1}$ and chitosan 100 concentrations as indicated.

and HTMA as a cationic surfactant combination is shown in Fig. 6.

Figures 3 and 4 can then be interpreted, based on the above assumption. The effective surface coverage of the droplets decreases when chitosan 100 is used, as compared when only HTMA is used as the surfactant. With increasing concentration of chitosan 100, the concentration of chitosan 100, adsorbed on the droplet surface, increases, and the effective surface coverage of the droplets thus decreases. This leads to increasing

Table 2. Dependence of concentration of HTMA or chitosan 100 on surface tension of miniemulsions and final latex

\begin{tabular}{|c|c|c|c|c|c|}
\hline Run & $\begin{array}{c}\text { HTMA } \\
\left(\mathrm{mmol} \mathrm{L}^{-1}\right)\end{array}$ & $\begin{array}{l}\text { Chitosan } \\
100 \text { (wt\%) }\end{array}$ & $\begin{array}{c}\text { Surface tension of } \\
\text { miniemulsion, } \gamma_{i}\left(\mathrm{mNm}^{-1}\right)\end{array}$ & $\begin{array}{c}\text { Surface tension of } \\
\text { final latex, } \gamma_{f}\left(\mathrm{mN} \mathrm{m}^{-1}\right)\end{array}$ & $\begin{array}{l}\Delta \gamma\left(\mathrm{mNm}^{-1}\right) \\
\left(\Delta \gamma=\gamma_{\mathrm{f}}-\gamma_{\mathrm{i}}\right)\end{array}$ \\
\hline $\mathrm{H} 1$ & 0 & 0.1 & - & - & \\
\hline $\mathrm{H} 2$ & 2 & 0.1 & 29.7 & 45.9 & 16.2 \\
\hline $\mathrm{H} 3$ & 4 & 0.1 & 28.5 & 40.1 & 11.6 \\
\hline $\mathrm{H} 4$ & 6 & 0.1 & 28.3 & 37.3 & 9.0 \\
\hline $\mathrm{H} 5$ & 10 & 0.1 & 25.5 & 32.7 & 7.2 \\
\hline $\mathrm{H} 6$ & 30 & 0.1 & 26.0 & 30.7 & 4.7 \\
\hline $\mathrm{CH} 1$ & 6 & 0 & 27.7 & 39.1 & \\
\hline $\mathrm{CH} 2$ & 6 & 0.2 & 22.7 & 33.8 & \\
\hline
\end{tabular}




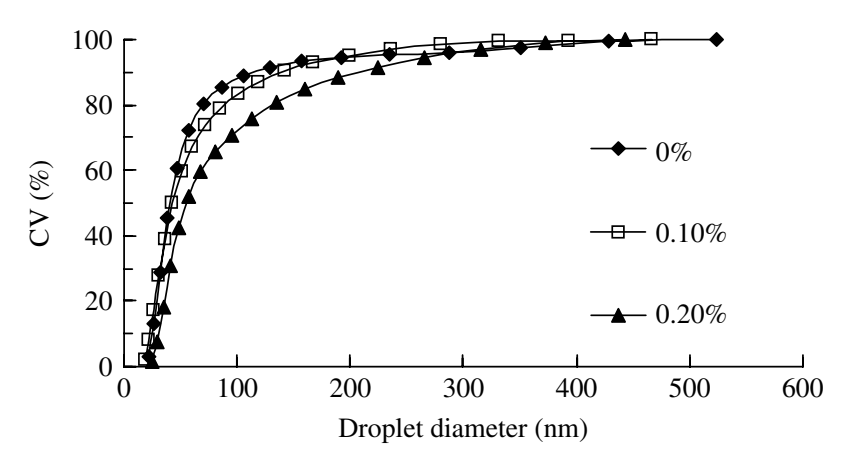

Figure 4. Cumulative volume, as a function of particle diameter, of the monomer droplets for critically stabilized miniemulsion of different concentrations of chitosan 100.

(a)

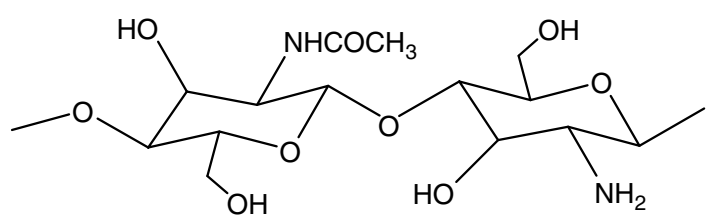

Figure 5. Chemical structure of chitosan 100, made up of (a) acetylated and (b) deacetylated units.

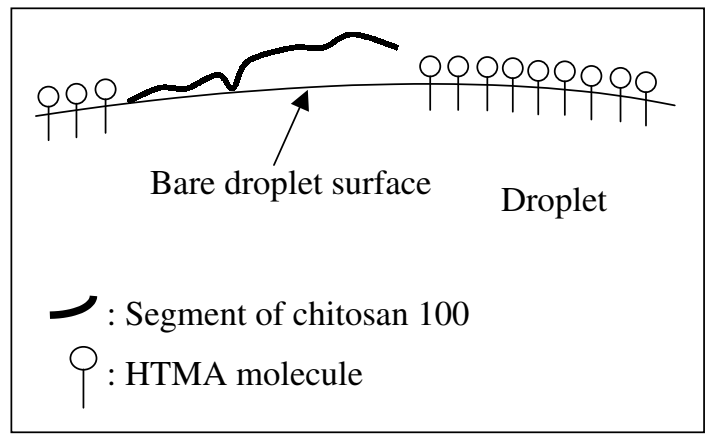

Figure 6. Schematic representation with chitosan 100 and HTAM as a cationic surfactant combination.

opportunity of collision coalescence of the droplets. The viscosity of the miniemulsion is also a factor. With increasing concentration of chitosan 100, the viscosity in the aqueous phase increases. The ultrasonication energy, dissipated in transportation, thus increases. The ultrasonication time for the droplets to reach a steady-state SD consequently increases.

\section{Effect of HTMA concentration on growth of latex particles}

The HTMA concentration was varied but the concentration of chitosan 100 was fixed at $0.1 \mathrm{wt} \%$ to study the effect of HTMA on nucleation and growth of latex particles in MMA miniemulsion polymerization. The SDs of monomer droplets of critically stabilized miniemulsions ${ }^{1,2}$ and corresponding final latex particles are shown in Fig. 7. The most striking feature is that the SDs of the steady-state droplets before polymerization and those of the resulting final latex particles are significantly different, except for
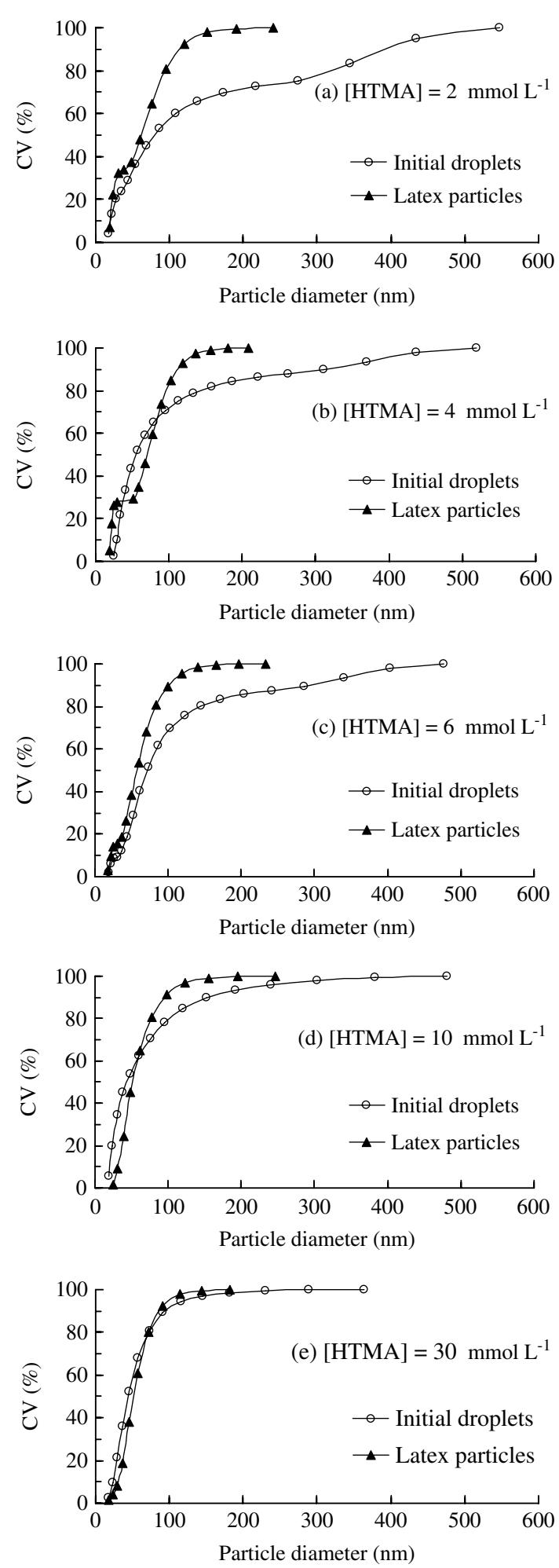

Figure 7. Cumulative volume, as a function of particle diameter, of the monomer droplets of critically stabilized miniemulsion and final latex particles for chitosan $100=0.1 \mathrm{wt} \%$ and HTMA concentrations as indicated.

cases $\left[\right.$ HTMA] $=10$ and $30 \mathrm{mmol} \mathrm{L}^{-1}$. For these two HTMA concentrations, the SDs of the droplets and the resulting final latex particles are nearly identical. But for $[\mathrm{HTMA}]=2,4$, and $6 \mathrm{mmol} \mathrm{L}^{-1}$, the $\mathrm{SD}$ of the final latex particles is a bimodal distribution with two major populations. The CV fraction of the smaller latex particles, with diameters 


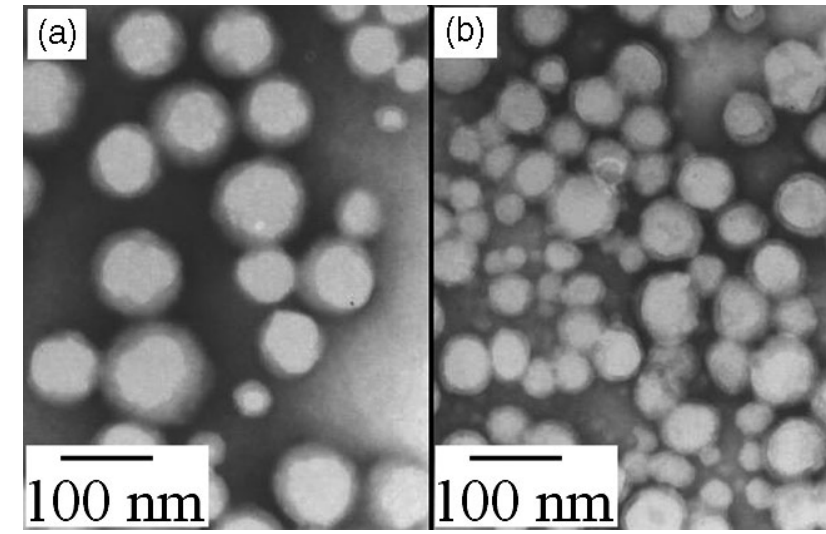

Figure 8. TEM micrographs of PMMA latex particles, polymerized with chitosan $100=0.1 \mathrm{wt} \%$ and $[\mathrm{HTMA}]=$ (a) $2 \mathrm{mmol} \mathrm{L}^{-1}$ and (b) $30 \mathrm{mmol} \mathrm{L}^{-1}$.

in the 20-30 nm range, decreases significantly with increasing HTMA concentration. The droplets, with diameters in the $250-600 \mathrm{~nm}$ range, disappear after polymerization.

The SD of the final latex particles was verified with TEM. Two micrographs of the PMMA latex particles are shown in Fig. 8(a) and (b), which were polymerized with [HTMA] $=2$ and $30 \mathrm{mmol} \mathrm{L}^{-1}$, respectively. For [HTMA] $=2 \mathrm{mmolL}^{-1}$, shown in Fig. 8(a), there is a bimodal SD of the final latex particles. Some are smaller than $30 \mathrm{~nm}$ in diameter, and others range from 50 to $100 \mathrm{~nm}$ in diameter. But for [HTMA] $=30 \mathrm{mmol} \mathrm{L}^{-1}$ (Fig. 8(b)) there is a unimodal distribution. All the final latex particles are in the range about $20-100 \mathrm{~nm}$ in diameter. For the other HTMA concentrations, the SDs of the final latex particles, obtained from TEM micrographs (not shown), are consistent with those obtained from measurements by DLS.

In the studied system, the miniemulsion was prepared in an ice bath to prevent monomer from polymerizing and other undesirable reactions; however, it is necessary to explore the SD of the droplets at elevated temperature because the mimiemulsion polymerization was conducted at $70^{\circ} \mathrm{C}$. The experimental formulation and preparation procedure were the same as those of run $\mathrm{H} 4$, listed in Table 2, except for $[\mathrm{V}-65]=0$. A sample was withdrawn immediately after the miniemulsion was ultrasonicated to reach a critically stabilized state. Then the critically stabilized miniemulsion was placed in a water bath, controlled at $70^{\circ} \mathrm{C}$, and a sample was withdrawn once again as the miniemulsion was heated for 12 and $24 \mathrm{~min}$, respectively. Each withdrawn sample was mixed with several drops of $1 \mathrm{wt} \%$ hydroquinone aqueous solution and immersed in an ice bath, and then the SD of the droplets was measured immediately. The results are shown in Fig. 9. It can be seen that the SDs of the droplets of the miniemulsion after reaching their critically stabilized state and after being heated for $12 \mathrm{~min}$ are consistent. In the studied system, conversion of the miniemulsion polymerization is as high as $90 \%$ after

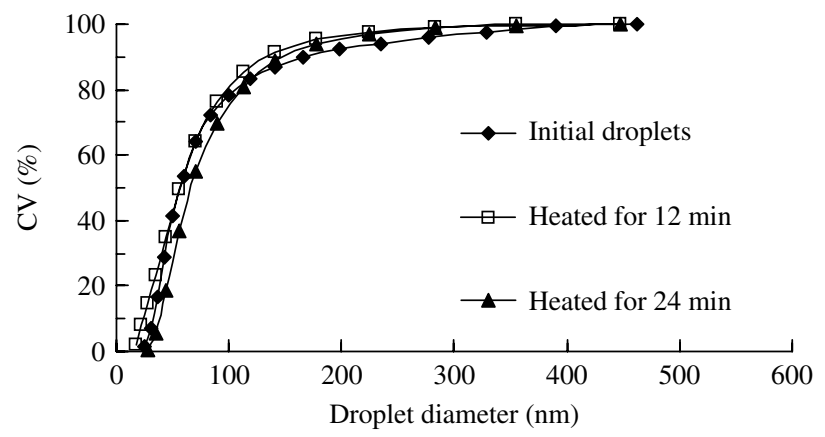

Figure 9. Size distributions of monomer droplets for MMA miniemulsion after homogenenization and after heating at $70^{\circ} \mathrm{C}$ for 12 and $24 \mathrm{~min}$.

reaction for $12 \mathrm{~min}$. This suggests the reason why the SDs of the droplets and the corresponding final latex particles, shown in Fig. 7(a)-(c), are significantly different, which is not primarily induced by the elevated temperature.

It has been found that for an oil-soluble initiator, the initiation is partitioned between oil and aqueous phases. ${ }^{28-31}$ For the initiation reaction in the aqueous phase, the main mechanism is due to desorption of the radicals into the aqueous phase. ${ }^{28}$ Therefore, as soon as V-65 starts its decomposition, radicals appear in both the oil and aqueous phases. Nucleation of the latex particles thus occurs in both phases. Meanwhile, homogeneous and/or micellar nucleation (secondary nucleation) cannot be ruled out because MMA is present or even saturated in the aqueous phase.

Based on the above analysis, the results in Fig. 7 can then be understood. For the lower HTMA concentration $\left([\mathrm{HTMA}]=2 \mathrm{mmol} \mathrm{L}^{-1}\right.$ as shown in Fig. 7(a)), the droplets can easily coalesce by collision because of the lower surface coverage of HTMA on the droplets. And after the start of the polymerization, MMA molecules diffuse easily out of the droplets into the aqueous phase. Therefore, the particles, nucleated from secondary nucleation, would obtain enough monomer supply to increase in volume. With increasing HTMA concentration ([HTMA] $=4$ and $6 \mathrm{mmol} \mathrm{L}^{-1}$ as shown in Fig. 7(b) and (c)), the $\mathrm{CV}$ fraction of the smaller latex particles decreases. This is ascribed to two factors. First, the droplet diameter of the monomer decreases with increasing surfactant concentration. ${ }^{1-10}$ Total surface area of the droplets thus increases considerably. Consequently, the droplets become more effective in capturing radicals from the aqueous phase, and the opportunity for the secondary nucleation is thus reduced. ${ }^{3,4,11}$ Second, the surface coverage of HTMA on the droplets also increases with increasing the surfactant concentration. Thus the particles, nucleated from secondary nucleation, would obtain less monomer supply to increase in size. When the HTMA concentration is increased to 10 and $30 \mathrm{mmol} \mathrm{L}^{-1}$ (shown in Fig. $7(\mathrm{~d}$ ) and (e)), the particles, nucleated from the secondary nucleation, 
would lack the monomer supply to continuously grow. They are too small to be stable and prone to be absorbed by the droplet particles. Droplet nucleation, consequently, dominates, and the SDs of the droplets and the final latex particles are nearly identical.

Surface tensions of the critically stabilized miniemulsions and the final latex, listed in Table 2, are also compared. It shows that all the surface tensions of the final latex $\left(\gamma_{\mathrm{f}}\right)$, in the studied range, are greater than those of the corresponding miniemulsions $\left(\gamma_{\mathrm{i}}\right)$. This implies that, after polymerization, fewer HTMA molecules dissolve in the aqueous phase. In other words, more HTMA molecules are adsorbed on the latex particles. In addition, $\Delta \gamma$ (where $\Delta \gamma=\gamma_{\mathrm{f}}-\gamma_{\mathrm{i}}$ ) also increases with decreasing HTMA concentration. This implies that the population of the final latex particles, nucleated from the secondary nucleation, increases with decreasing HTMA concentration. The results are in agreement with those in Fig. 7.

\section{Effect of concentration of chitosan 100 on growth of latex particles}

The concentration of chitosan 100 was varied but HTMA concentration was fixed at $6 \mathrm{mmol} \mathrm{L}^{-1}$ to study the effect of chitosan 100 on nucleation and growth of latex particles in MMA miniemulsion polymerization. SDs of steady-state monomer droplets before polymerization and those of the resulting final latex particles are shown in Fig. 10(a)-(c) for chitosan $100=0,0.1$, and $0.2 \mathrm{wt} \%$, respectively. For chitosan $100=0$ (Fig. 10(a)), the SDs of the droplets and the final latex particles are almost identical. This indicates that when only HTMA is used as the surfactant, the droplets can be stabilized, and the opportunity of collision coalescence of the droplets is effectively reduced. Thus droplet nucleation dominates. With increasing concentration of chitosan 100 to 0.1 and $0.2 \mathrm{wt} \%$ (Fig. 10(b) and (c)), the SD of the final latex particles is not consistent with that of the droplets. As described above, this is due to decreasing the effective surface coverage of chitosan 100 and HTMA on the droplets with increasing concentration of chitosan 100 . It leads to more chitosan 100 and HTMA dissolved in the aqueous phase. Besides, the increase of bare surface of the droplets promotes the opportunity of collision coalescence of the droplets and the diffusion of MMA molecules into the aqueous phase after the start of the polymerization, comparative to that in Fig. 10(a). Therefore particles that were nucleated from the secondary nucleation increased. Surface tensions of the critically stabilized miniemulsions for different concentrations of chitosan 100 and the corresponding final latex, listed in Table 2, are compared. It shows that all the surface tensions of the final latex are greater than those of the corresponding miniemulsions. This indicates that, after polymerization, less chitosan 100 and HTMA dissolve in the aqueous phase.
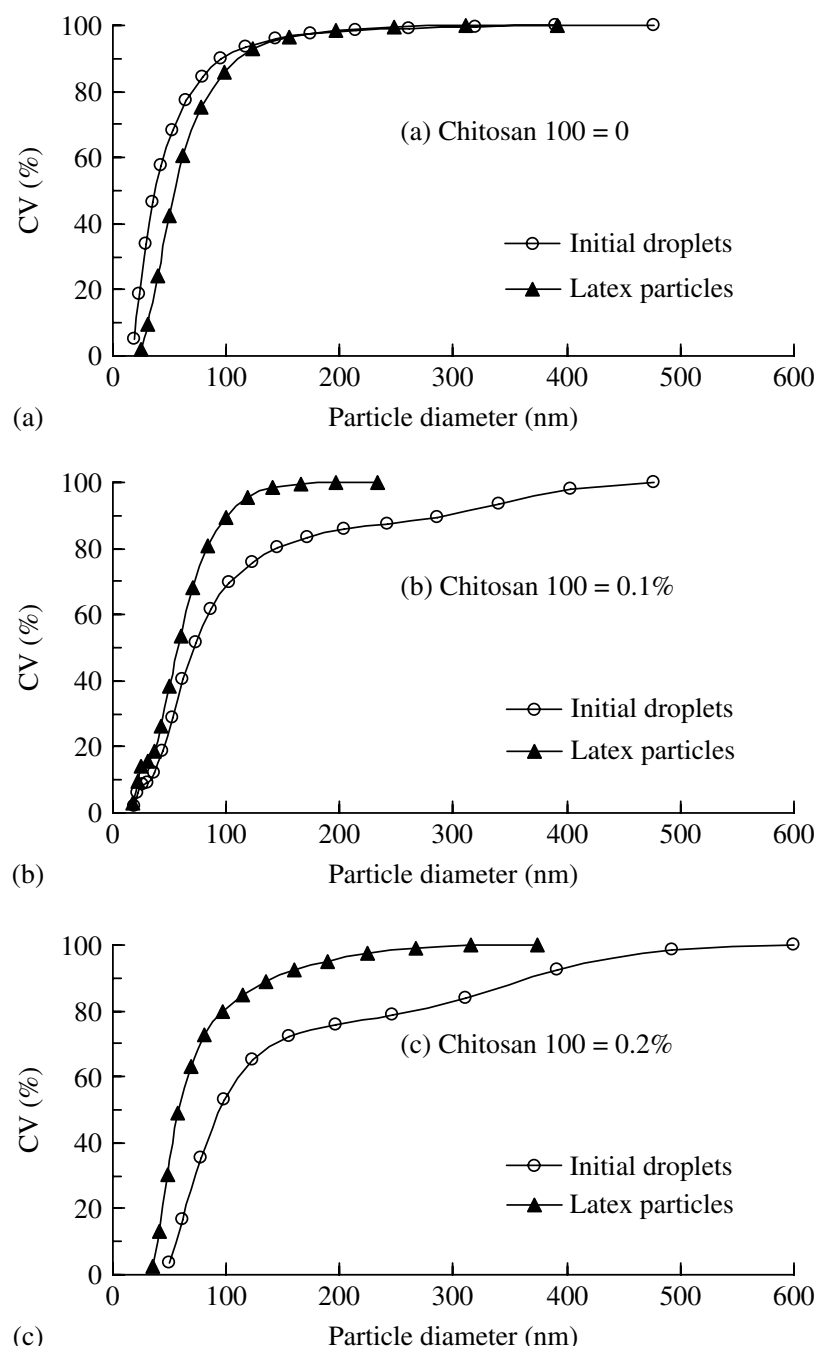

Figure 10. Cumulative volume, as a function of particle diameter, of the monomer droplets of the critically stabilized miniemulsion and final latex particles for $[\mathrm{HTMA}]=6 \mathrm{mmol} \mathrm{L}^{-1}$ and chitosan 100 concentrations as indicated.

\section{CONCLUSIONS}

The effect of the concentration of HTMA or chitosan 100 on SD of monomer droplets during ultrasonication and on growth of latex particles for MMA mininemulsion polymerization was studied. With increasing ultrasonication time, the miniemulsions with different concentrations of HTMA or chitosan 100 show an initially broad multimodal SD of the droplets and later reached their critically stabilized state in which a monodisperse SD of the droplets is obtained. With increasing HTMA concentration or decreasing concentration of chitosan 100, the required ultrasonication time for the miniemulsion to reach the critically stabilized state is significantly reduced, and the SD of the steady-state droplets shifts towards smaller droplet diameter.

Polymerization was conducted on critically stabilized miniemulsions at elevated temperature. For lower HTMA concentrations, the SDs of the final latex particles are different from those of the corresponding droplets and bimodal distributions with two major populations are obtained. The reason why the SDs of 
the droplets and the corresponding final latex particles are significantly different is not primarily induced by the elevated temperature but by initiation by the oilsoluble initiator, V-65, in both oil and aqueous phases. Droplet nucleation and secondary nucleation thus occur simultaneously in miniemulsion polymerization. For higher HTMA concentrations, droplet nucleation dominates, because both SDs for the droplets and the resulting final latex particles are nearly identical.

For chitosan $100=0$ and $[\mathrm{HTMA}]=6 \mathrm{mmol} \mathrm{L}^{-1}$, the SDs of the droplets and the resulting final latex particles are almost identical. This indicates that when HTMA only is used as the surfactant, the droplets can be stabilized, and the opportunity of collision coalescence of the droplets is effectively reduced. Thus droplet nucleation dominates. With increasing concentration of chitosan 100 to 0.1 and $0.2 \mathrm{wt} \%$, the $\mathrm{SD}$ of the final latex particles is not consistent with that of the droplets. This is due to a decrease of the effective surface coverage of chitosan 100 and HTMA on the droplets with increasing concentration of chitosan 100 . The possibility of secondary nucleation thus increases during polymerization.

\section{ACKNOWLEDGEMENTS}

The authors thank Ying-Da Luo, Sin-Hao Chiang, and Chia-Cheng Lin of National Taiwan University for their help with the experiments.

\section{REFERENCES}

1 Landfester K, Bechthold N, Tiarks F and Antonietti M, Macromolecules 32:5222 (1999).

2 Antonietti M and Landfester K, Prog Polym Sci 27:689 (2002).

3 Asua JM, Prog Polym Sci 27:1283 (2002).

4 Capek I and Chern CS, Adv Polym Sci 155:101 (2001).

5 Chern CS and Chen TJ, Colloid Polym Sci 275:546 (1997).
6 Huang H, Zhang H, Li J, Cheng S, Hu F and Tan B, f Appl Polym Sci 68:2029 (1998).

7 Wang S, Poehlein GW and Schork FJ, $\mathcal{f}$ Polym Sci Polym Chem 35:595 (1997).

8 Lim MS and Chen H, F Polym Sci Polym Chem 38:1818 (2000).

9 Miller CM, Venkatesan J, Silebi CA, Sudol ED and EIAasser MS, $\mathcal{f}$ Colloid Interf Sci 162:11 (1994).

10 Reimers JL and Schork FJ, $\mathcal{F}$ Appl Polym Sci 60:251 (1996).

11 Chern CS, Liou YC and Chen TJ, Macromol Chem Phys 199:1315 (1998).

12 Douglas SJ, Illum L and Davis SS, $\mathcal{F}$ Colloid Interf Sci 103:154 (1985).

13 Durand A and Dellacherie E, Colloid Polym Sci 284:536 (2006).

14 Marie E, Landfester K and Antonietti M, Biomacromolecules 3:475 (2002).

15 Yang SC, Ge HX, Hu Y, Jiang XQ and Yang CZ, Colloid Polym Sci 278:285 (2000).

16 Chern CS, Lee CK and Ho CC, $\mathcal{F}$ Polym Sci Polym Chem 37:1489 (1999).

17 Chern CS, Lee CK and Ho CC, Colloid Polym Sci 277:507 (1999).

18 Schulz PC, Rodriguez MS, Del Blanco LF, Pistonesi M and Agullo E, Colloid Polym Sci 276:1159 (1998).

19 Mun S, Decker EA and McClements DJ, Langmuir 21:6228 (2005).

20 Mun S, Decker EA and McClements DJ, $\mathcal{f}$ Colloid Interf Sci 296:581 (2006).

21 Perrin P, Porcar I and Tribet C, Polym Int 52:465 (2003).

22 Landfester K, Rothe R and Antonietti M, Macromolecules 35:1658 (2002).

23 Qiu G, Wang Q, Wang C, Lau W and Guo Y, Polym Int 55:265 (2006).

24 Cunningham M, Xie M, McAuley K, Keoshkerian B and Georges M, Macromolecules 35:59 (2002).

25 Moad G, Chiefari J, Chong YK, Krstina J, Mayadunne RTA, Postma A, et al, Polym Int 49:993 (2000).

26 Min KE, Mei Li and Matyjaszewski K, f Polym Sci Polym Chem 43:3616 (2005).

27 Chern CS and Chang HT, Polym Int 51:1428 (2002).

28 Asua JM, Rodriguez VS, Sudol ED and El-Aasser MS, $\mathcal{F}$ Polym Sci Polym Chem 27:3569 (1989).

29 Nomura M and Fujita K, Macromol Rapid Commun 10:581 (1989).

30 Alduncin JA, Forcada J, Barandiaran MJ and Asua JM, $\mathcal{F}$ Polym Sci Polym Chem 29:1265 (1991).

31 Capek I, Adv Colloid Interf Sci 91:295 (2001). 